\title{
Skeletal effects of oral oestrogen compared with subcutaneous oestrogen and testosterone in postmenopausal women
}

\author{
M Savvas, J W W Studd, I Fogelman, M Dooley, J Montgomery, B Murby
}

\section{Structured Abstract}

Study objective-To compare oral and implanted oestrogens for their effects in preventing postmenopausal osteoporosis.

Design-Non-randomised cohort study of postmenopausal women treated with oral or depot oestrogens and postmenopausal controls.

Setting-Gynaecological endocrine clinic in tertiary referral centre.

Patients-Oral treatment group of 37 postmenopausal women (mean age 57.5 years, median 8.75 years from last menstrual period), compared with 41 women given oestrogen implants (mean age 56.2 years, median 9.5 years from last menstrual period) and 36 controls (mean age 51.8 years, median 2.0 years from last menstrual period). Weight was not significantly different among the groups.

Interventions-Oral treatment group was given continuous treatment with cyclic oestrogen and progesterone preparations (Prempak $\mathrm{C}$ or Cycloprogynova) for a median of 8.0 years. Implant group was given subcutaneous implants of oestradiol $50 \mathrm{mg}$ combined with testosterone $100 \mathrm{mg}$, on average six monthly for a median of $8 \cdot 5$ years. Controls were not treated.

End point-Significant increase in bone density.

Measurements and main results-Bone density measured by dual beam photon absorptiometry was 1.02 (SD 0.13) $\mathrm{g}$ hydroxyapatite $/ \mathrm{cm}^{2}$ in implant group versus $0.89(0.11)$ in oral group $(p<0.01)$ and 0.87 $(0.14)$ in controls $(p<0.01)$. Serum oestradiol concentration in implant group was (median) $725 \mathrm{pmol} / \mathrm{l}$ versus $170 \mathrm{pmol} / \mathrm{l}$ in oral group $(\mathbf{p}<0.01)$ and $99 \mathrm{pmol} / \mathrm{l}$ in controls $(\mathbf{p}<0.01)$. Serum follicular stimulating hormone was median 1 IU/1 (range 1-11) in implant group (equivalent to premenopausal values) versus $43(4-94) \mathrm{IU} / \mathrm{l}$ in oral group $(p<0.01)$ and $72(28-99) \mathrm{IU} / \mathrm{l}$ in controls $(\mathrm{p}<0.01)$.

Conclusions-Subcutaneous oestrogen is more effective than oral oestrogen in preventing osteoporosis, probably owing to the more physiological (premenopausal) serum oestradiol concentrations achieved. It also avoids problems of compliance that occur with oral treatment.

Department of Nuclear Medicine, Guy's Hospital, London SE1 9RT

I Fogelman, MD, consultant B Murby, BSC, senior physicist

Correspondence and requests for reprints to: $\mathrm{Mr}$ J W W Studd, Dulwich Menopause Clinic, Dulwich Hospital, London SE22 8PT.

\section{Introduction}

Peak bone mass is achieved in the fourth decade of life in both men and women, after which it decreases with age. The rate at which bone is lost accelerates in women after the menopause to the extent that they have lost half of their skeletal calcium by the age of 70 . This leads to the excess of osteoporotic fractures in women compared with men. Albright et al were the first to show the value of oestrogen in preventing

\begin{tabular}{|c|c|c|c|}
\hline & \multirow[b]{2}{*}{ Controls } & \multicolumn{2}{|c|}{ Women receiving: } \\
\hline & & $\begin{array}{c}\text { Oral } \\
\text { oestrogen }\end{array}$ & $\begin{array}{l}\text { Oestradiol and } \\
\text { testosterone } \\
\text { implants }\end{array}$ \\
\hline $\begin{array}{l}\text { No of women } \\
\text { Mean (SD) age (years) } \\
\text { Mean (SD) weight }(\mathrm{kg} \text { ) } \\
\text { Median (range) years from menopause } \\
\text { Median (range) years of treatment } \\
\text { Median (range) years of amenorrhoea before treatment }\end{array}$ & $\begin{array}{l}36 \\
51 \cdot 8(4 \cdot 1) \\
62 \cdot 5(6 \cdot 5) \\
2 \cdot 0(1-7) \\
2(1-7)\end{array}$ & $\begin{array}{l}37 \\
57 \cdot 5(6 \cdot 6) \\
60 \cdot 7(8 \cdot 0) \\
8 \cdot 5(2-25) \\
8(1-20) \\
1(1-19)\end{array}$ & $\begin{array}{l}41 \\
56 \cdot 2(7 \cdot 4) \\
63 \cdot 3(8 \cdot 7) \\
9 \cdot 5(2-18) \\
8 \cdot 5(1-22) \\
1(1-19)\end{array}$ \\
\hline
\end{tabular}

postmenopausal osteoporosis, ${ }^{1}$ and several prospective studies have confirmed their results. ${ }^{2-4}$

Oestrogens may be given orally as tablets or percutaneously as implants, creams, or patches. ${ }^{5}$ Although oral treatment is standard, subcutaneous implantation is a simple technique that can be performed as an outpatient procedure under local anaesthesia. ${ }^{6}$ Subcutaneous administration has several advantages: the enterohepatic circulation is avoided, gastrointestinal symptoms are reduced, and the ratio of oestradiol to oestrone achieved is physiologically appropriate. Oral treatment results in an abnormal ratio favouring oestrone as a result of conversion of oestradiol to oestrone in the liver. The percutaneous route also has the advantage that it can be used to give testosterone, if indicated, which avoids the hepatotoxic effects of oral methyltestosterone.

We investigated in a cross sectional study the effects of the route of administration of oestrogen in women attending our clinic who had been treated satisfactorily with oestrogen by various routes for many years for various menopausal symptoms. We compared them with a control group of postmenopausal women who had not started treatment with oestrogen and were attending our clinic for the first time.

\section{Patients and methods}

Table I shows the characteristics of the 114 women studied. They were postmenopausal as defined by amenorrhoea for at least one year with a serum follicle stimulating hormone concentration of more than $15 \mathrm{IU} / \mathrm{l}$. Bone density was compared in a control group consisting of 36 untreated women (mean age 51.8 years; median time since last menstrual period $2 \cdot 0$ years); 37 women (mean age 57.5 years; median time since last menstrual period 8.5 years) who had been treated with oral oestrogens for a median of $8 \cdot 0$ years; and 41 women (mean age 56.2 years; median time since last menstrual period $9 \cdot 5$ years) who had been treated with subcutaneous implants of oestradiol and testosterone for a median of 8.5 years. The women treated either orally or subcutaneously, depending on their preference, had had amenorrhoea for a median of one year before starting their treatment.

All women with a uterus who were receiving oral oestrogens had their treatment supplemented with cyclic progestogen (either the combined preparation Prempak C, containing 12 days' supply of norgestrel (23 women), or Cyclo-progynova, containing 10 days' supply of levonorgestrel (six)). Women with a uterus receiving hormonal implants were given cyclic norethisterone $5 \mathrm{mg}$ daily for the first seven to 13 days of each calendar month to prevent endometrial disorders. ${ }^{8}$ Hormonal implantation was carried out under local anaesthesia during a routine visit to the clinic, the pellets being inserted into the subcutaneous fat of the anterior abdominal wall. The usual dose was oestradiol $50 \mathrm{mg}$ combined with testosterone $100 \mathrm{mg}$. Rarely, the oestradiol dose was increased to 75 or $100 \mathrm{mg}$. Implantation was repeated as symptoms of the climacteric returned, at about six month intervals, and at these visits bone density was measured and hormones assayed.

Bone density was estimated in the spine at L2-4 and in the neck of the right femur with a Novo 22A BMC-LAB dual photon absorptiometer with gadolinium- 153 as the source of radiation. ${ }^{9}$ The ab- 
sorptiometer was standardised with a solution radiologically equivalent to hydroxyapatite, and the results were expressed as grams of hydroxyapatite per unit projected area of bone. The precision of this technique is $1-3 \%$ and the accuracy $2-5 \% .^{10}$

Statistical analysis-Data on the bone density, age, and weight of the three groups of patients were normally distributed and were therefore compared by the non-paired Student's $t$ test. All other variables were analysed with the Mann-Whitney U test as they were not normally distributed.

\section{Results}

The women in the two treatment groups were not significantly different in terms of their age, weight, years since the menopause, duration of treatment, or duration of amenorrhoea before treatment. The women in the control group were significantly younger and were fewer years past the menopause $(p<0.01)$.

Table II summarises the measurements of bone density and plasma concentrations of sex hormones in the three groups. Bone density was significantly increased in the women receiving subcutaneous oestradiol and testosterone compared with the two other groups. In the group receiving oral oestrogens the median serum oestradiol concentration was slightly but not significantly increased compared with that in the control group and the median follicle stimulating hormone concentration was significantly reduced but remained within the postmenopausal range. Women receiving subcutaneous oestrogen and testosterone had a significantly increased median serum oestradiol concentration and a significantly decreased follicle stimulating hormone concentration compared with the other women.

TABLE II-Bone density and serum concentration of sex hormones in untreated women and women who had been treated with hormones

\begin{tabular}{|c|c|c|c|}
\hline & \multirow[b]{2}{*}{ Controls } & \multicolumn{2}{|c|}{ Women receiving: } \\
\hline & & $\begin{array}{c}\text { Oral } \\
\text { oestrogen }\end{array}$ & $\begin{array}{l}\text { Oestradiol and } \\
\text { testosterone } \\
\text { implants }\end{array}$ \\
\hline Mean (SD) bone density in spine ( $\mathrm{g}$ hydroxyapatite $\mathrm{cm}^{2}$ ) & $0.87(0 \cdot 14)$ & $0.89(0.11)$ & $1 \cdot 02(0 \cdot 13)^{\star} \dagger$ \\
\hline $\begin{array}{l}\text { Mean (SD) bone density in neck of femur } \\
\left(\mathrm{g} \text { hvdroxyapatite } / \mathrm{cm}^{2}\right)\end{array}$ & $0.73(0 \cdot 10)$ & $0.74(0.08)$ & $0.80(0 \cdot 10)^{\star}+$ \\
\hline Median (range) serum follicle stimulating hormone (IU/) & $72(28-99)$ & $43(4-94) \dagger$ & $1(1-11)^{\star} \dagger$ \\
\hline Median (range) serum oestradiol $(\mathrm{pmol} / \mathrm{i}$ & $99(44-580)$ & $170(30-651)$ & $725(372-2370)^{\star} \dagger$ \\
\hline Median (range) serum testosterone (nmol /) & $1 \cdot 00(0 \cdot 3-2 \cdot 7)$ & $0 \cdot 50(0 \cdot 3-2 \cdot 2)$ & $0.90(0 \cdot 4-2 \cdot 4)$ \\
\hline
\end{tabular}

tp<0.01 Compared with women receiving oral oestrogen

\section{Discussion}

This study confirms the value of oestrogen replacement treatment in preventing postmenopausal loss of bone. The bone density in the spine and neck of the femur in untreated women was maintained in women given a median of 8.0 years of oral treatment but was significantly increased in women who had been treated for a median of 8.5 years with subcutaneous implants of oestradiol and testosterone. The difference between the two treatment groups cannot be explained by a difference in the duration of amenorrhoea before treatment. All of the women receiving subcutaneous oestradiol also received testosterone but at a dosage that reputedly does not have any significant effect on bone." The effect of androgens is, however, an important therapeutic variable that needs further evaluation, which is now being done.

The current recommended dose of oral oestrogen for relieving menopausal symptoms and protecting the skeleton is $0.625 \mathrm{mg}$ or $1.25 \mathrm{mg}$ conjugated equine oestrogens or the equivalent dose of oestradiol valerate. ${ }^{12}$ The serum oestradiol concentration at this dose will, however, be only slightly raised and the follicle stimulating hormone concentration will remain in the postmenopausal range. ${ }^{131+}$ Several studies have shown that higher concentrations of oestradiol are achieved by subcutaneous implantations; the effect was cumulative when implantation was repeated every six months. 11 is This is due to the metabolic advantages of the percutaneous route and the elimination of non-compliance, which is reputed to occur in up to $70 \%$ of women prescribed oral oestrogens as replacement treatment. ${ }^{16}$ Despite the cumulative effects of repeated implantation on plasma oestradiol concentrations no harmful effects have been identified on blood pressure, coagulation of blood, or glucose tolerance." Percutaneous treatment is an efficient route of administering oestrogen as many metabolic changes occurring in the enterohepatic system are avoided and an appropriate ratio of oestradiol to oestrone of about 2:1 results. ${ }^{78}$ We believe that the difference in bone density between the two treatment groups was due to the higher serum oestradiol concentrations achieved with subcutaneous implants of oestrogen (725 v $170 \mathrm{pmol} / \mathrm{l}$ ).

The precise mechanism whereby patients receiving oestrogen implants gain bone is unclear. The higher serum oestradiol concentrations achieved with implantation may stimulate osteoblasts directly, leading to a true gain in bone, or may be more effective in suppressing resorption of bone, thus permitting some recovery of early postmenopausal loss of bone. All women had first started treatment on average about one year after the menopause, a time when rapid postmenopausal bone loss would be expected and therefore when most could be gained by inhibiting resorption of bone and allowing the resulting spaces to be refilled. The increase in bone mass in the women receiving subcutaneous implants was greater in the spine than in the proximal femur, probably because the vertebral bodies consist predominantly of trabecular bone, which has a greater surface area and is metabolically more active than the cortical bone, which predominates in the femoral neck. ${ }^{19}$ Nevertheless, Keil et al suggested that even fairly short exposure to oral oestrogen within four years after the menopause may confer long term protection against fracture of the hip. ${ }^{20}$

Despite the original suggestions of Albright et al that the collagen of the bone matrix was important,' most recent work on postmenopausal osteoporosis has concentrated on calcium and the hormones regulating calcium, with conflicting results. The generalised loss of collagen in the body that occurs with decreasing oestrogen concentrations may be the primary factor causing postmenopausal osteoporosis. The association of osteoporosis with thin skin is well recognised, and we recently showed that there is a $40 \%$ decline in the collagen content and thickness of the skin after the menopause that cannot only be prevented with oestrogen but can be corrected to normal values within nine months after the start of percutaneous treatment. ${ }^{21} 22$ Decreased skin thickness with reduced collagen content has been associated with osteoporosis in anorexia nervosa (Savvas et al, unpublished results). The loss of collagen in the skin has been estimated at $1-3 \%$ a year and is similar to the rate at which bone is lost after the menopause, which suggests that the collagen in bone may behave similarly to that in skin. ${ }^{23}$ After loss of the matrix calcium would be lost as a secondary effect independent of dietary calcium or hormones regulating calcium. The observations that osteoporotic bone has a reduced collagen content ${ }^{24}$ and that oestrogen receptors are present on osteoblasts (F S Kaplan et al, unpublished results) support this concept.

Clearly, the cornerstone of preventing osteoporosis must now be oestrogen replacement treatment. The results of our cross sectional study confirm the protec- 
tive effect of oral oestrogens and show an apparent increase in bone mass after treatment with subcutaneous oestradiol and testosterone.

We thank Birthright for its financial support, which made this work possible, and D Cooper and D Lowe, of the computer unit, King's College School of Medicine and Dentistry, for their help with the statistical analysis.

1 Albright F, Smith PH, Richardson AM. Postmenopausal osteoporosis; its clinical features. 7 AMA 1941;116:2465-74

2 Lindsay R, Aitken JM, Anderson JB, Hart DM, MacDonald EB, Clarke AC. Long term prevention of postmenopausal osteoporosis by oestrogen. Lancet 1976;i:1038-41

3 Nachtigall LE, Nachtigall RH, Nachtigall RD, Beckman EM. Estrogen replacement therapy: a ten year prospective study in the relationship to osteoporosis. Obstet Gynecol 1979;53:277-81.

4 Christiansen C, Christiansen MS, Transbol I. Bone mass in postmenopausal women after withdrawal of oestrogen/gestagen replacement therapy. Lancet 1981;i:459-61.

5 Studd JWW, Anderson HM, Montgomery JC. Hormonal treatment, selection of patients-kind and duration of treatment. In: Greenblatt RB, de Gruyter of patients-kind and duration of treatment. In: Greenblatt RB, de Gruyter
W, eds. A modern approach to the menopause. Berlin: de Gruvter, 1986: W, eds

6 Thom M, Studd JWW. Procedures in practice: hormone implantation. $\mathrm{Br}$ Med F 1980; : $648-50$.

7 Studd JWW, Magos AL. Hormone pellet implantation for the menopause and premenstrual tension. Obstet Gynecol Clin North Am 1987;14:229-49.

Studd JWW, Thom M. Oestrogens and endometrial carcinoma. In: Studd JWW, ed. Progress in obstetrics and gunaecologv. Vol 1. London: Churchill Livingstone, 1981:182-98

9 Neilsen SP, Krolner BL. Photon-beam absorptiometry. In: Dixan ASJ, Russell RGG, Stamp TCB, eds. Osteoporosis-a multidisciplinary problem. Sumposium No 55, International Congress of the Royal Society of Medicine. London: Academic Press, 1983:105-8.

10 Murby B, Fogelman I. Bone mineral measurements in clinical practice. $\mathrm{Br}$. Hosp. Med 1987;37:453-8.
11 Barlow EH, Abdulla HI, Roberts ADG, Al Azzawi F, Leggate I, Hart DM Long term hormone implant therapy-hormonal and clinical effects. Obste Gynecol 1986;67:321-5

12 Lindsay R, Hart DM, Clark DM. The minimum effective dose of estrogen for the prevention of post-menopausal bone loss. Obstet Gynecol 1984;63:759.

13 Powers MS, Schenkel L, Darey PE, Good WR, Balestra JC, Place VA. Pharmacokinetics and pharmacodynamics of transdermal forms of 17 estradiol: comparison with conventional oral estrogens used for hormone replacement. Am f Obstet Gynecol 1985;152:1099-106.

14 Chetkowski RJ, Meldrum DR, Steingold KA, et al. Biologic effects of transdermal estradiol. N Engl I Med 1986;314:1615-20.
the

15 Cardozo LD, Gibb DMF, Studd JWW, Tuck SM, Thom MH, Cooper DJ. The use of hormone implants for climacteric symptoms. Am 7 Obstet Gynecol 1984;148:336-7.

16 Ravnikar VA. Compliance with hormone therapy. Am 7 Obstet Gynecol $1987 ; 15: 1332-4$

17 Studd JWW, Dubiel M, Kakkar VV, Thom M, White PJ. The effects of hormone replacement therapy on glucose tolerance, clotting factors, fibrinolysis and platelet behaviour in post-menopausal women. In: Cooke ID, ed. The role of oestrogen/progestogen in the management of the menopause. Lancaster: MTP Press, 1978:41-59.

18 Thom M, Collins WP, Studd JWW. Hormonal profiles in postmenopausal women after therapy with subcutaneous implants. Br $\mathcal{F}$ Obstel Gynaecol $1981 ; 88: 426-33$

19 Smith R. Osteoporosis: cause and management. Br Med f 1987;294:329-32.

20 Keil DP, Felson DT, Anderson JJ, Wilson DWF, Moskowitz MA. Hip fractures and the use of estrogens in postmenopausal women. $N$ Engl f Med 1987;317:1169-74

21 Brincat M, Moniz CF, Studd JWW, et al. The long term effects of the menopause and of administration of sex hormones. Br 7 Obstet Gynaecol 1985;92:256-9.

22 Brincat M, Versi E, Moniz CF, Magos A, De Trafford J, Studd JWW. Skin collagen changes in post-menopausal women receiving different regimes of estrogen therapy. Obstet Gynecol 1987;70:123.

23 Savvas M, Brincat M, Studd JWW. Postmenopausal osteoporosis. Br f Hosp Med 1987;38:16.

24 Birkenhager-Frenkel DH. A significant lack of collagen in osteoporotic bone. In: Christiansen C, Johansen JS, Riis BJ, eds. Proceedings of the international symposium on osteoporosis. Copenhagen: Osteopress Aps, 1987:443-5.

(Accepted 12 April 1988)

\section{Reversal of renal failure in nephritis associated with antibody to glomerular basement membrane}

\section{A P Maxwell, W E Nelson, Claire M Hill}

Renal Unit, Belfast City Hospital, Belfast BT9 7AB A P Maxwell, MRCP, registrar

W E Nelson, MRCP, consultant nephrologist

Institute of Pathology, The Queen's University of Belfast, Belfast BT12 6BA Claire M Hill, MRCPATH, senior lecturer

Correspondence to: Dr Nelson.
Nephritis associated with antibody to glomerular basement membrane generally presents as rapidly progressive renal failure. Histological examination shows crescentic nephritis with linear deposits of IgG on the glomerular basement membrane. Pulmonary haemorrhage may occur. Effective treatment comprises immunosuppression and plasma exchange.' Recovery of useful renal function is considered to be unlikely but has been reported in patients dependent on dialysis. ${ }^{2}$ We describe such a case in a patient with acute oliguric renal failure.

\section{Case report}

A 35 year old woman was referred in March 1987 with a one month history of tiredness and nausea. She complained of haematuria and oliguria but did not have any respiratory symptoms. She had a history of essential hypertension, which had been treated with a thiazide diuretic. Her renal function had been normal eight months earlier. On examination her blood pressure was normal and she did not have a rash. Radiographic examination of her chest showed no abnormalities. Her haemoglobin concentration was $101 \mathrm{~g} / \mathrm{l}$, urine volume $0.4 \mathrm{l}$, serum creatinine concentration $435 \mu \mathrm{mol} / 1$, and creatinine clearance $12 \mathrm{ml} /$ minute. Her urine showed haematuria and red cell casts on microscopy.

Two days later her renal function had deteriorated further (serum creatinine concentration $715 \mu \mathrm{mol} / \mathrm{l}$ and creatinine clearance $2 \mathrm{ml} /$ minute). She underwent haemodialysis, after which percutaneous renal biopsy was performed. On histological examination two of the four glomeruli obtained showed florid necrotising crescentic glomerulonephritis; there was an inflammatory reaction around the glomeruli and associated tubulointerstitial tissue. The other two glomeruli showed mild mesangial hypercellularity. No arteriolar lesions were observed. Immunofluorescence showed strongly positive linear deposits of $\mathrm{IgG}$ along the surviving capillary walls of the glomeruli. Her serum contained a high titre ( $80 \%)$ of antibody to glomerular basement membrane (normal value $<12 \%$ ) and a transient low titre of antibody to the cytoplasm of neutrophils on radioimmunoassay.

Treatment with $3 \mathrm{mg}$ cyclophosphamide $/ \mathrm{kg}, 60 \mathrm{mg}$ prednisolone, and daily plasma exchange (4 litres) was started. The titre of antibody to glomerular basement membrane decreased to normal values (figure). She

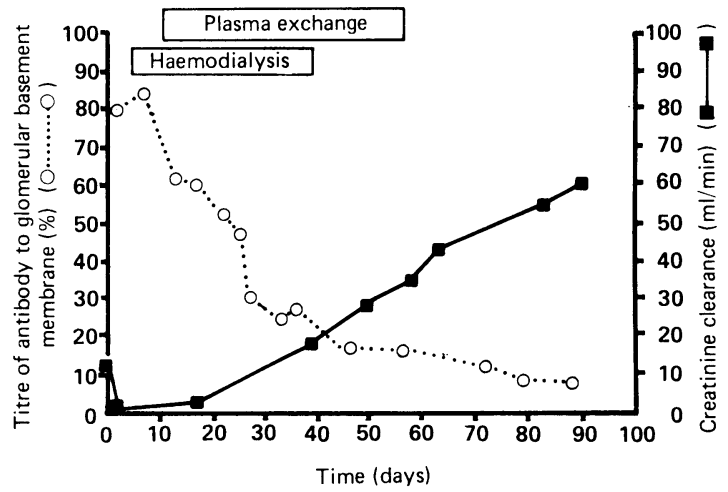

Changes in titre of antibody to glomerular basement membrane and creatinine clearance during treatment with plasma exchange and cyclophosphamide and prednisolone

remained dependent on dialysis for four weeks; subsequently her renal function gradually recovered almost to normal (serum creatinine concentration $140 \mu \mathrm{mol} / 1$ and creatinine clearance $60 \mathrm{ml} /$ minute). Plasma exchange was stopped after six weeks and cyclophosphamide after eight weeks. Ten months after 